\title{
Erratum to: Spices and Condiments
}

\author{
Anurudh Kumar Singh
}

\section{Erratum to:}

\section{Chapter 11 in: A.K. Singh, Wild Relatives of Cultivated Plants in India, https://doi.org/10.1007/978-981-10-5116-6_11}

The original version of the book was inadvertently published with an incorrect image for Fig 11.2 (b) in page 139. This image has now been replaced with the correct image as given below. 


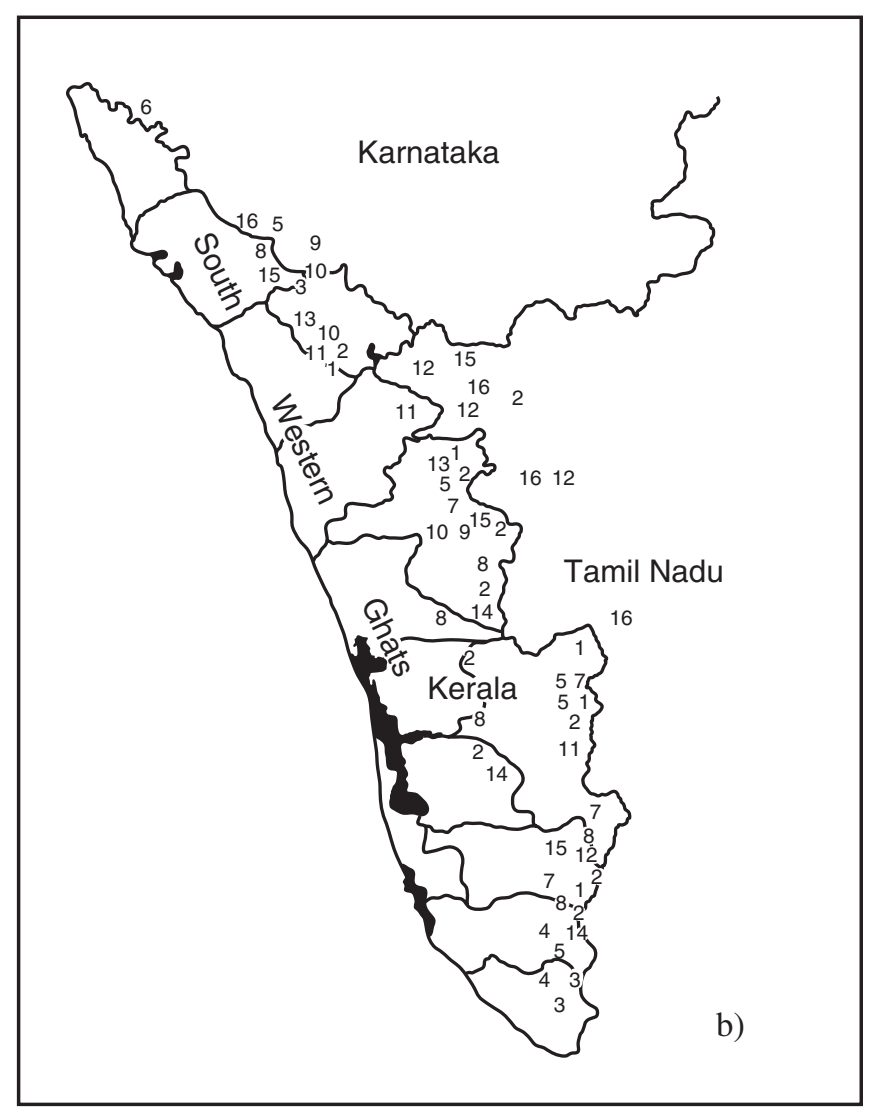

In addition, the author corrections have also been incorporated in the Appendix II. 